assuming the interaction forces between a proton and a neutron which are given by the considerations developed by Heisenberg, Majorana and Wigner. They have obtained the transition probability in the usual quantum-mechanical way, and their result gives a value for the cross-section of the same order as the experimental value, but rather greater, if we take the mass of the neutron as $1 \cdot 0080$. If, however, we take the experimental value for the cross-section, the calculations lead to a neutron mass of $1 \cdot 0085$, which seems rather high. Thus the agreement of theory with experiment may be called satisfactory but not complete.

One further point may be mentioned. Some experiments of Lea ${ }^{B}$ have shown that paraffin wax bombarded by neutrons emits a hard $\gamma$-radiation greater in intensity and in quantum energy than when carbon alone is bombarded. The explanation suggested was that, in the collisions of neutrons and protons, the particles sometimes combine to form a diplon, with the emission of a $\gamma$-ray. This process is the reverse of the one considered here. Now if we assume detailed balancing of all processes occurring in a thermodynamical equilibrium between diplons, protons, neutrons and radiation, we can calculate, without any special assumption about interaction forces, the relative probabilities of the reaction (1) and the reverse process. Using our experimental value for the cross-section for reaction (1), we can calculate the cross-section for the capture of neutrons by protons for the case when the neutrons have a kinetic energy $2(h \nu-W)=1.0 \times 10^{6}$ electron volts in a co-ordinate system in which the proton is at rest before the collision. In this special case the crosssection $\sigma_{c}$ for capture (into the ground state of the diplon-we neglect possible higher states) is much smaller than the cross-section $\sigma_{p}$ for the 'photo-effect'. It is unlikely that $\sigma_{c}$ will be very much greater for the faster neutrons concerned in Lea's experiments. It therefore seems very difficult to explain the observations of Lea as due to the capture of neutrons by protons, for this effect should be extremely small. A satisfactory explanation is not easy to find and further experiments seem desirable.

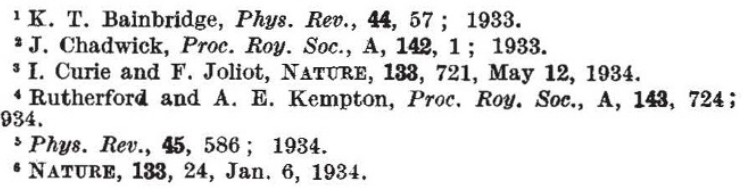

1 K. T. Bainbridge, Phys. Rev., 44, 57 ; 1933.

2 J. Chadwick, Proc. Roy. Soc., A, 142, 1 ; 1933.

4 Rutherford and A. E. Kempton, Proc. Roy. Soc., A, 143, 724 ;

'Phy8. Rev., 45, 586; 1934.

- Nature, 133, 24, Jan. 6, 1934.

\title{
Ancient Indian Iron
}

\section{By S. C. BRITTon, Salters Fellow, University Metallurgical Laboratories, Cambridge}

$\mathrm{I}^{\mathrm{T}}$ appears certain that iron was known in India at a very early date. Mention of its production in ancient writings puts the earliest time of production earlier than 1,000 B.c. According to Herodotus ${ }^{1}$, the Indian contingent of the army of Xerxes were using iron for military purposes about 500 B.c. The description of iron surgical instruments in an ancient medical work, the excavation of iron weapons from burial sites and the presence to this day of masses of iron like the pillars of Delhi and Dhar all indicate that the production of iron steadily increased as the centuries passed.

The methods of production and qualities of Indian iron and steel seem to have early excited the curiosity of the British conquerors and in 1795, Dr. George Pearson ${ }^{2}$ published a paper on a kind of steel named 'wootz', then being manufactured in Bombay. The methods of analysis and examination then available only allowed the vague conclusions that the metal was very hard, had about 0.03 per cent carbon, and was believed to have been produced by direct reduction of the ore. Dr. Buchanan's "Travels in the South of India", published in 1807, describes the native Indian processes for iron and steel production then employed, which were believed to be those handed down from previous ages. Numerous other investigations have been made since that time, which increase in thoroughness as methods of examination have improved.

\section{The Delhi Pillar}

The Delhi pillar has constantly aroused interest. Sir Alexander Cunningham, in the "Archæological Survey of India", published during the years 1862-65, reported the pillar as a solid shaft of wrought iron, upwards of sixteen inches in diameter and twenty-two feet in length; he mentions the curious yellow colour of the upper part of the shaft, which at one time caused the belief that the pillar was of bronze. This appearance has been commented upon by many observers since that time. Inscriptions made on the pillar are said still to be perfectly clear and sharp, and these have allowed the approximate date of its erection to be fixed as A.D. 310 .

There seems little doubt that the pillar was built up by welding together discs of iron; it is said that the marks of welding can still plainly be seen $^{3}$. Sir Robert Hadfield examined a small specimen of the pillar in 1911 and afterwards was able to make a fairly detailed investigation of a larger piece 4 . The analysis showed the composition C, 0.08 ; Si, 0.046 ; Mn, 0 ; P, 0.114 ; N, 0.032 ; $\mathrm{Fe}, 99 \cdot 72 ; \mathrm{Cu}$ and other elements, $0 \cdot 034$. Hadfield described the iron as an excellent type of wrought iron entirely free from inclusions, being better from the point of view of homogeneity and purity than the best modern Swedish charcoal irons. The structure was found to consist of large grains of ferrite with a very small portion of cementite, sometimes located in the grain boundaries and 
occasionally in the ground mass. A smaller grain structure, independent of the large one, was faintly visible, and there were also a large number of small lines in a regular formation which appeared to be related to the small grain structure; this was mentioned as possibly due to an aging effect. A specimen of the pillar rusted in a single night when water was placed on it in Hadfield's laboratory, but the fractured surface suffered no change in four days when merely exposed to the laboratory atmosphere ${ }^{5}$ Hadfield mentions that the part of the pillar below the ground had suffered from corrosion.

\section{The Dhar Pillar}

The great iron pillar found at Dhar is described in detail by Cousins ${ }^{6}$. The pillar is in three portions, having apparently been fractured during religious disturbances in the fourteenth and fifteenth centuries A.D. There are no original inscriptions on the pillar itself, or sufficiently definite references elsewhere, to give a basis for any but the vaguest conjecture about the date of manufacture. Its form suggests that it belongs to the Gupta period (A.D. $320-480$ ), and the general belief is that it is approximately contemporaneous with the Delhi pillar.

The original Dhar pillar appears to have been approximately 50 feet long with an average section of 104 square inches and a weight of about 7 tons, and, like the Delhi pillar, it seems to have been constructed by welding together discs of wrought iron. There are a number of holes in the pillar of about $1 \frac{1}{4}$ in. diameter and varying from $1 \frac{3}{4}$ in. to 3 in. in depth, which Cousins ${ }^{6}$ suggests were intended to hold tommy-bars for turning the mass whilst it was being forged; the finding of the broken end of a bar jammed into one of the holes lends some support to this idea. Sir Robert Hadfield has examined a specimen of the pillar ${ }^{7}$, and found it to be wrought iron having C, $0.02 ; \mathrm{P}, 0.28$; Fe, 99.6 . The Brinell ball hardness varied considerably and irregularly over the material, the limits being 240 and 121 ; the fracture was bright and crystalline, showing laminations. Further analyses and micrographical investigation by C. J. Smithells and by Prof. Cobb have shown no new features in the iron; it is found to rust fairly quickly in a laboratory atmosphere ${ }^{8}$.

\section{Ancrent Sinhalese IroN}

The first thorough investigation of ancient Indian steel was made by Sir Robert Hadfield in 1911-12 ${ }^{\circ}$. He was able to examine a number of ancient implements which had been excavated from the buried cities of Ceylon. Many such implements have been unearthed; they are very heavily rusted and apparently continue to rust in the atmosphere of the Museum of Colombo, unless very carefully protected. Nevertheless, the presence of a considerable quantity of yet unchanged iron shows a marked resistance to corrosion. An ancient Sinhalese chisel, dating back to the fifth century, was found to have the percentage composition, iron, $99 \cdot 3$; phosphorus, 0.28 ; sulphur, 0.003 ; silicon, 0.12 ; no manganese and only traces of carbon with about 0.3 per cent of slag and oxide inclusions. Examination of microsections led Hadfield to believe that the chisel had been carburised, had originally been quenched, but had become partially tempered during the long lapse of time. A nail and an ancient billhook of similar age and origin showed a similar analysis. All the specimens contained a large amount of slag in lumpy irregular form. The low sulphur content was held to indicate that the metal was originally produced by charcoal reduction of the ore. The microscopical examination suggested that the specimens were rather similar to modern puddled iron, and this was further borne out to some extent by mechanical tests.

\section{The Iron Beams at Konarak}

A number of large iron beams which were apparently used in the construction of the collapsed Black Pagoda at Konarak are still lying amid the ruins of the temple in varying states of preservation. The date most generally accepted for the building of the temple is about 1240 A.D., and it is presumed that the beams were made at that time. Their appearance is fully described by Graves ${ }^{10}$.

There are some twenty-nine massive bars, most of them broken in the collapse of the building; the largest two are approximately 35 feet long by about 8 inches square and $25 \frac{1}{2}$ feet long by 11 inches square respectively. They show very definite evidence of having been fabricated by welding up small blooms, commonly 2 inches by 1 inch in section and 6 inches long. Many of the broken ends show the existence of irregular and sometimes uniform cavities from which small pieces of cinder can be raked. Some of the beams are very heavily rusted, but many of them are scarcely affected and have a very thin and closely adherent coating. A specimen taken from one of the beams has been examined by Friend and Thornycroft'11. The presence of many cracks, containing slag inclusions, rendered micrographical investigation difficult. The cracks were found to be bordered by bands of ferrite, the grain boundaries being faintly discernible. Portions of the specimen more distant from the cracks showed a fairly uniform structure, typical of a mild steel containing rather less than $0 \cdot 15$ per cent carbon. The metal was found to be very soft, having a Brinell hardness number of 72. Analysis of a piece chosen as free from slag showed $\mathrm{C}, 0 \cdot 110$; $\mathrm{Si}, 0 \cdot 100 ; \mathrm{S}, 0.024$; $\mathrm{P}, 0.015 ; \mathrm{Mn}$, a trace.

An attempt was made to compare the resistance to corrosion of the metal with that of a modern mild steel of unspecified composition. One weighed specimen of each was exposed to alternate wetting by tap-water and drying for one year ; reweighing 
after removal of rust showed that the ancient iron had suffered a loss amounting to 89 per cent of that of the modern steel. The specimens were then exposed to the action of an artificial seawater for a year and again the ancient iron lost less weight than the modern steel, losses being in the ratio $75: 100$. However, tests of this kind, made on single specimens, and including only one modern steel, really show very little about the corrosion resistance of the ancient metal.

\section{Miscellaneous Specimens}

The so-called Pillar of Heliodorus at Besnagar, which is itself of stone, is supported at its base by iron wedges which are still in a partial state of preservation. It is believed that the pillar was erected about 125 в.c. and that the iron supports were used from the outset. However, there is a possibility that the metal was not native India iron, but was imported from Greece. Hadfield has examined a sample of it and describes it ${ }^{\mathbf{1 2}}$ as the only ancient ferrous specimen which can be called steel; he actually demonstrated that it could be hardened by quenching. The structure was pearlitic, having elongated and irregularly disposed crystals of sorbitic pearlite upon a ferrite ground mass; after quenching from $850^{\circ} \mathrm{C}$. in water, a specimen became martensitic. There were seams of slag in some portions. Analysis showed C, 0.70 ; Si, 0.04 ; S, 0.008 ; P, 0.020 ; Mn, 0.02 ; Cr, a trace; Fe, 99 . The Brinell hardness number was 146.

W. Rosenhain ${ }^{13}$ mentions ancient iron chains which assisted pilgrims to climb Adam's Peak,
Ceylon. These have been worn round and smooth, but are apparently uncorroded. Rosenhain suggested that the links have corroded down to a cinder layer so that the outside remaining is apparently only a cinder surface protecting the iron below ; specimens cut and brought to London rusted as quickly as any other iron. Graves ${ }^{14}$ gives a list of 239 pieces of iron ranging up to 17 feet long and up to 6 inches by 4 inches section used in the construction of the Garden Temple at Puri, which was built not later than the first half of the twelfth century. However, no further information on these is available.

Iron swords and daggers of uncertain date have been unearthed from burial sites in the district of Tinnevelly and specimens of third century iron have been recovered from Buddha Gaya ${ }^{15}$ but no examination appears to have been made.

It seems possible that many specimens of iron exist in India of which the date of manufacture cannot be established, but which may well be ancient, and there are no doubt others of ascertainable date yet to be excavated from the earth.

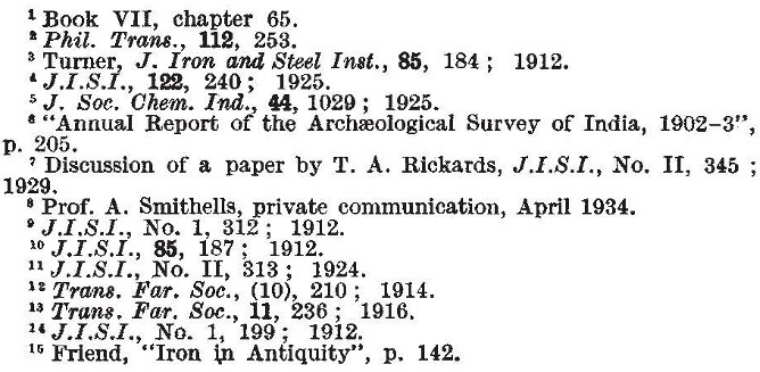

(To be continued.)

\section{Samuel Pierpont Langley (I834-I906)}

$\mathrm{O}^{\mathrm{N}}$ $\mathrm{N}$ August 22, the centenary of the birth of Samuel Pierpont Langley will be com. memorated at the Smithsonian Institution, Washington. Langley was secretary of the Institution from 1887 until 1906 ; it was there he made his valuable investigations in aeronautics and to him was due the inauguration of both the Astrophysical Observatory and the National Zoological Park, which, like the United States National Museum and the Bureau of American Ethnology, are integral parts of the Institution. Much of his experimental apparatus is preserved in the Museum, and it has accordingly been arranged for a special exhibit devoted to his activities and honours to be unveiled on the hundredth anniversary of his birth. The exhibit is being arranged by Mr. T. T. Belote, curator of the Division of American History, and it will ultimately be one of four recalling his own work and that of his two predecessors, Joseph Henry, who was secretary from 1846 until 1878, and Spencer Fullerton Baird, who held the office from 1878 until 1887, and of his successor, Charles Doolittle Walcott, who was secretary from 1907 until 1927. It is also intended to direct attention to Langley's work in the Press, and to publish a special memoir of him containing some extracts from his writings.

Langley was born at Roxbury, Massachusetts, on August 22, 1834, and died at the age of seventyone years on February 27, 1906, at Aiken, South Carolina. The son of a wholesale merchant of Boston, he came of a family connected with many of the most eminent men in the history of Massachusetts, and grew up in an atmosphere which stimulated his original and inquiring mind. Even as a mere child, he had the use of a telescope, and he once declared that he could not remember when he was not interested in astronomy. Like all the family, he was an omnivorous reader and when, as a youth of seventeen years, he left the Boston High School, he had laid the foundation of his knowledge of English, French and German classics. On leaving school he took up civil engineering and architecture, and at the age of twenty-three years went westward, spending seven years in Chicago and St. Louis. Of this 